\title{
Consequences of orthodontic treatment in malocclusion patients: clinical and microbial effects in adults and children
}

\author{
Li Guo ${ }^{1 *}$, Ying Feng ${ }^{1}$, Hong-Gang Guo², Bo-Wen Liu ${ }^{3}$ and Yang Zhang ${ }^{3}$
}

\begin{abstract}
Background: Malocclusion is a common disease of oral and maxillofacial region. The study was aimed to investigate levels changes of periodontal pathogens in malocclusion patients before, during and after orthodontic treatments, and to confirm the difference between adults and children.

Method: One hundred and eight malocclusion patients (46 adults and 62 children at the school-age) were randomly selected and received orthodontic treatment with fixed orthodontic appliances. Subgingival plaques were Porphyromonas gingivalis (P.gingivalis), Fusobacterium nucleatum (F. nucleatum), Prevotella intermedia (P. intermedia) and Tannerella forsythensis ( $T$. forsythensis) collected from the observed regions before and after treatment. Clinical indexes, including plaque index (PLI), gingival index (GI), sulcus bleeding index (SBI), probing depth (PD) and attachment loss (AL) of observed teeth were examined.
\end{abstract}

Results: The detection rates of P.gingivalis, F. nucleatum, P. intermedia and T. forsythensis increased from baseline to the third month without significant difference, and then returned to pretreatment levels 12 month after applying fixed orthodontic appliances. Adults' percentage contents of P.gingivalis, F. nucleatum, P. intermedia and T. forsythensis were significantly higher than those of children at baseline and the first month, but not obvious at the third month. PLI and SBI were increased from baseline to the first and to the third month both in adults and children groups. Besides, PD were increased from baseline to first month, followed by a downward trend in the third month; however, all patients were failed to detect with AL.

Conclusions: Periodontal and microbiological statuses of malocclusion patients may be influenced by fixed orthodontic appliances in both adults and children, more significant in children than in adults. Some microbiological indexes have synchronous trend with the clinical indexes. Long-term efficacy of fixed orthodontic appliances for malocclusion should be confirmed by future researches.

Keywords: Malocclusion, Orthodontic treatment, Fixed orthodontic appliances, Pathogens

\section{Background}

Malocclusion together with dental caries and periodontal disease are known as the three most common diseases in oral and maxillofacial regions $[1,2]$. Malocclusion is defined as a misalignment of the teeth or an incorrect occlusion between the upper and lower dental arches [3]. Malocclusion has a significant effect on craniofacial development, oral health and function, as well as the

\footnotetext{
* Correspondence: gl1092740779@sina.com

'Department of Stomatology, Ninth Hospital of Xi'an, No. 151, 2nd Ring Road East, Xi'an 710054, People's Republic of China

Full list of author information is available at the end of the article
}

patients' appearance, and more serious to induce harm to systemic health of patients. Fixed orthodontic appliances is one of the most important methods applied in the course of orthodontic treatment due to its convenience and efficiency $[4,5]$. Commonly used by orthodontists, fixed orthodontic appliances may result in a majority of complications at the same time, such as gingival inflammation or swelling, bleeding, hyperplasia and even slight attachment loss (AL) during treatment [6]. Besides, the stagnant zones created around fixed orthodontic appliances are in favor of the accumulation of bacterial plaques, and their colonization and reproduction [7]. Since 
the incidence of periodontitis increases with age [8], it is inadequate to determine that the orthodontic treatment of the juvenile period is related to the occurrence of periodontitis after middle age. With respect to the above, there is a need to clarify clinical and microbial effects of orthodontic treatment with fixed orthodontic appliances in children and adults to provide theoretical basis for the treatment of periodontal disease.

At present, researches on the relationship between fixed orthodontic appliances and periodontal disease focus more on clinical parameters on the basis of quantitative PCR Technology, instead of the effect of fixed orthodontic treatment of periodontal bacteria. There are some related subgingival periodontopathogens reported in previous studies, such as Porphyromonas gingivalis (P.gingivalis), Fusobacterium nucleatum (F. nucleatum), Prevotella intermedia (P. intermedia) and Tannerella forsythensis (T. forsythensis), which have been suggested to possess close relationships with the development of chronic periodontitis [9-11]. Furthermore, to confirm the effect of fixed orthodontic appliances on periodontal tissue and oral microecological changes, simultaneous detection of specific pathogenic bacteria and clinical indexes is therefore needed to clarify current concerns. Oral microecological balance is indeed the basis of maintaining oral health in the human body [12]. The dynamic variation of P.gingivalis, $F$. nucleatum, $P$. intermedia and T. forsythensis and clinical examinations for periodontal tissues were therefore taken in this study to interpret basic characteristics of periodontal tissues of malocclusion patients and the difference between adults and children.

\section{Methods}

\section{Study subjects}

The study incorporated a total of 108 malocclusion patients (ranging from 8 to 32 years old) admitted in the Ninth Hospital of Xian during December 2010 to December 2013. Among them, there were 46 adults (18-32 years old) and 62 children at the school-age (8-15 years old). After recruitment, written informed consents were obtained from each participant and their guardians (mainly children) before the enrollment and the performance of the study. The diagnosis of malocclusion was in strict accordance with the criteria mentioned by Grabowski et al. [13] and Oliveira et al. [14]. In addition, following inclusion criteria were as applied: (1) patients who were confirmed to have no previous history of periodontal diseases or oral mucosal diseases; (2) patients without caries or dental fillings; (3) patients without obvious oral habits, without the habit of gum swelling or bleeding history; (4) patients who did not take antibiotics or hormones therapies one month before the experiment; (5) female patients who did not in their menstrual, pregnancy or lactation period; (6) patients had no previous history of systemic diseases or other factors that might affect bone metabolism. All patients were treated by straight wire appliance after diagnosis. The first molars were banded and a $0.5-1.0 \mathrm{~mm}$ diameter tube was soldered on the palatal side of the first molar band; also, the premolars were braced. The first molars and the premolars were all attached with $1.1 \mathrm{~mm}$ diameter stainless steel retaining wires (Reward, China).

\section{Experimental methods and periodontal clinical index}

Both sides of mandibular central incisors and the mandibular first/second premolars were selected as the observed teeth. In addition, patients' periodontal statuses were recorded and established at their first visit to the hospital. By using a single blind method that the clinician was unaware of the experiment status, the periodontal examination was done by the same clinician with a labeled periodontal probe (YDM, Japan). Plaque index (PLI) [15], sulcus bleeding index (SBI) [16], probing depth (PD) [17] and AL [18] of observed teeth were examined in triplicates.

Subgingival plaques were collected at medial and distal buccal axial ridge of the observed teeth at three different time points (baseline data of before orthodontic treatment, one month and three months after treatment), and stored at $-70{ }^{\circ} \mathrm{C}$ for further usage. Subsequently, frozen samples were dissolved at room temperature of $37^{\circ} \mathrm{C}$, and then were concussed uniformly with a vortex oscillator, washed with Tris- $\mathrm{HCl}$ buffer wash once, lysozyme cleavage, followed by a conventional phenolchloroform extraction procedure. The DNA sample were finally stored at $-20{ }^{\circ} \mathrm{C}$ for real-time polymerase chain reaction (real-time PCR) experiment.

\section{Quantitative real-time PCR}

The collected DNA samples were studied using realtime PCR according to the manufacturer's instructions [19]. The experiment was repeated three times with similar results. PCR primers were designed by Primer Premier 5.0 software (PREMIER Biosoft International, Palo Alto, CA, USA) and were synthesized by Invitrogen Biotechnology Co., Ltd (Beijing). The positive controls of P.gingivalis, F. nucleatum, P. intermedia and T. forsythensis were the standard bacterial strains provided from the laboratory of Ninth Hospital of Xi'an. Table 1 showed primer sequences and their lengths [20-22]. The $25 \mu \mathrm{l}$-PCR system contained $10 \times$ buffer $(2.5 \mu \mathrm{l})$, $2.5 \mathrm{mmol} / \mathrm{L}$ dNTP Mixture $(2.0 \mu \mathrm{l}), 25 \mathrm{mmol} / \mathrm{L} \mathrm{MgCl}_{2}$ $(2.5 \mu \mathrm{l}), 20 \mu \mathrm{mol} / \mathrm{L}$ for each forward and reverse primers (1 $\mu \mathrm{l}$ each), $5 \mathrm{U} / \mu \mathrm{l}$ Taq DNA polymerase $(0.15 \mu \mathrm{l})$ (Tiangen, China), Template $2.5 \mu \mathrm{l}$ and then made up to a final volume of $25 \mu \mathrm{l}$ using double-distilled water. The PCR protocol on Light Cycler (LC480) (Roche Diagnostics, Mannheim, Germany) for P.gingivalis was: an initial 
denaturation step $\left(95{ }^{\circ} \mathrm{C}\right.$ for $5 \mathrm{~min}$ ) and 36 cycles of denaturation $\left(95{ }^{\circ} \mathrm{C}\right.$ for $30 \mathrm{~s}, 60^{\circ} \mathrm{C}$ for $1 \mathrm{~min}$ and $72{ }^{\circ} \mathrm{C}$ for $1 \mathrm{~min})$ followed by annealing and extension steps $\left(72{ }^{\circ} \mathrm{C}\right.$ for $2 \mathrm{~min})$. An initial denaturation step at $94{ }^{\circ} \mathrm{C}$ for $5 \mathrm{~min}$ was conducted for the remaining three indexes, followed by 30 cycles of denaturation $\left(94{ }^{\circ} \mathrm{C}, 94{ }^{\circ} \mathrm{C}\right.$ and $95{ }^{\circ} \mathrm{C}$ for $30 \mathrm{~s}$ for $F$. nucleatum, $P$. intermedia and T. forsythensis, respectively, $60{ }^{\circ} \mathrm{C}$ for $30 \mathrm{~s}$ and $72{ }^{\circ} \mathrm{C}$ for $1 \mathrm{~min}$ ) and the final annealing and extension steps $\left(72{ }^{\circ} \mathrm{C}\right.$ for $2 \mathrm{~min}$, $2 \mathrm{~min}$, and $3 \mathrm{~min}$, respectively).

\section{Agarose gel electrophoresis}

The PCR products were subsequently separated by electrophoresis in $0.3 \%$ agarose gels. The final images were then acquired and observed in a ChemiDoc (Bio-Rad, Hercules, USA) gel documentation system.

\section{Statistical analysis}

Data analysis was performed using SPSS software (Version 17.0; SPSS, Chicago, IL). $t$ test was applied in the study to analyze differences between adults and children at the same time points, as well as the difference within the adults group and the children group at different time points. A bilateral $P$ value of less than 0.05 was considered statistically significant.

\section{Results}

\section{The detection results of microbial indicators}

On the day following the removal of fixed orthodontic appliances, the positive percentage of the four pathogens was $40.1,66.0,32.0$ and $48.9 \%$, respectively. Besides, as for the total counts of bacteria detected by real-time PCR, corresponding results were shown in Table 2. Furthermore, detection rates of the four pathogens showed stable trends among adults during three different time points. But the total detection rates in children increased overtime. Besides, as for the differences between adults and children at the same time points, the detection rates in adults exhibited obvious elevated percentages of pathogens both at baseline and after treatment than in children, but without apparent differences (all $P>0.05$ ).
In addition, as shown in Table 2, as compared to the baseline levels, percentage contents of the four pathogens in adults and children as well as the total percentage all indicated increased tendencies one month and three months after treatment. Besides, the percentage of total sample was significantly higher three months after treatment than that of the baseline level, with statistical differences (all $P<0.05$ ). Adult percentage contents were significantly higher than that of children at baseline for all pathogens, and at one month after treatment for P.gingivalis, F. nucleatum, $P$. intermedia and T. forsythensis (all $P<0.05$ ), but there was no significant difference between adults and children in the third months after treatment except for $T$. forsythensis (all $P>0.05$ ).

\section{The detection results of $\mathrm{PLI}, \mathrm{SBI}, \mathrm{PD}$ and $\mathrm{AL}$}

Adults, children, and overall PLI measurements increased with time triply. Among them, when compared to that before treatment at the baseline level, PLI was significantly higher in adults one month and three months after treatment. PLI also showed a significant increase in Children three months after treatment than those levels at baseline. Overall measurements of PLI was also increased obviously one month and three months after treatment than in that at baseline, with a more significant increase trend three months after treatment. At baseline, there were significant less PLI measured in adults than in children, but there was no significant difference in the other two time points of detection (Table 3).

Adults, children, and overall SBI examination were also increased with time, such level was evidently increased one month and three months after treatment than these at baseline, with statistical significance (all $P<0.05$ ). But there was no significant difference of SBI in patients received treatment one month and three months later, and no obvious statistical difference was found between adults and children at three different time points, respectively (all $P>0.05$ ).

Adult and children DP were increased from baseline to first month, followed by a downward trend in the

Table 1 Primer sequences for P.gingivalis, F. nucleatum, P. intermedia and T. forsythensis

\begin{tabular}{|c|c|c|}
\hline & Sequences & Amplified fragment length \\
\hline \multirow[t]{2}{*}{ P.gingivalis } & F: 5'-AGGCAGCTTGCCATACTGCG-3' & $404 \mathrm{bp}$ \\
\hline & R: 5'-ACTGTTAGCAACTACCGATGT-3' & \\
\hline \multirow[t]{2}{*}{ F. nucleatum } & F: 5'-AGAGTTTGATCCTGGCTCAG-3' & $408 \mathrm{bp}$ \\
\hline & R: 5'-GTCATCGTGCACACAGAATTGCTG-3' & \\
\hline \multirow[t]{2}{*}{ P. intermedia } & F: 5'-CGTGGACCAAAGATTCATCGGTGGA-3' & $259 \mathrm{bp}$ \\
\hline & R: 5'-CCGCTITACTCCCCAACAAA-3' & \\
\hline \multirow[t]{2}{*}{ T. forsythensis } & F: 5'-GCGTATGTAACCTGCCCGCA-3' & $641 \mathrm{bp}$ \\
\hline & R: 5'-TGCTTCAGTGTCAGTTATACCT-3' & \\
\hline
\end{tabular}


Table 2 The percentage contents and detective amount of the P.gingivalis, F. nucleatum, P. intermedia and T. forsythensis in adults and adolescents

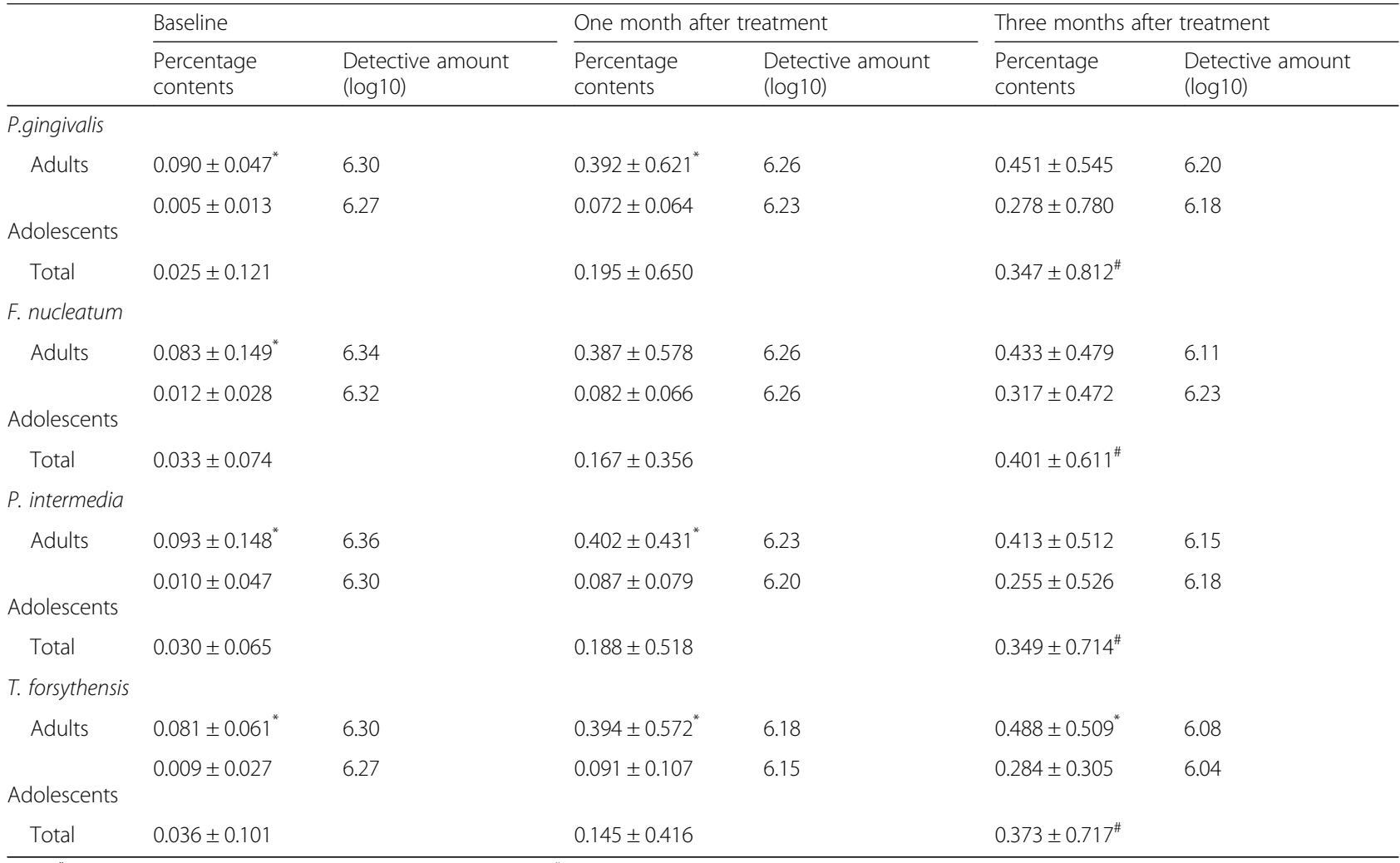

Note: ${ }^{*}$, compared with the percentage of adolescents, $P<0.05$; ${ }^{\#}$, compared with the percentage at baseline, $P<0.05$

third month after treatment. DP showed obvious higher levels in children treated for one month and three month than those at baseline. There was significant difference regarding PD between adults and children at baseline, but not significant at other time points after treatment. In addition, PD in all the included 108 patients were all less than or equal to $1-2 \mathrm{~mm}$ in the three repeated tests. Furthermore, throughout the experiment, all 108 patients were not detected with AL in the triplicate test.

Table 3 Detection results of clinical indicators, PLI, SBI and PD, in adults and adolescents

\begin{tabular}{|c|c|c|c|}
\hline & Baseline & One month after treatment & Three month after treatment \\
\hline \multicolumn{4}{|l|}{ PLI } \\
\hline Adults & $0.195 \pm 0.311^{\mathrm{a}}$ & $0.610 \pm 0.512^{*}$ & $0.780 \pm 0.531^{*}$ \\
\hline Adolescents & $0.491 \pm 0.367$ & $0.637 \pm 0.444^{*}$ & $0.899 \pm 0.490^{*}$ \\
\hline Total & $0.345 \pm 0.292$ & $0.680 \pm 0.463^{*}$ & $0.876 \pm 0.462^{*}$ \\
\hline \multicolumn{4}{|l|}{ SBI } \\
\hline Adults & $0.253 \pm 0.412$ & $1.123 \pm 0.503^{*}$ & $1.119 \pm 0.148^{*}$ \\
\hline Adolescents & $0.278 \pm 0.457$ & $0.993 \pm 0.492^{*}$ & $1.002 \pm 0.481^{*}$ \\
\hline Total & $0.283 \pm 0.505$ & $0.976 \pm 0.0 .484^{*}$ & $0.984 \pm 0.0 .496^{*, \#}$ \\
\hline \multicolumn{4}{|l|}{ PD } \\
\hline Adults & $0.056 \pm 0.122^{\mathrm{a}}$ & $1.188 \pm 0.164^{*}$ & $1.047 \pm 0.148^{*}$ \\
\hline Adolescents & $1.015 \pm 0.101$ & $1.190 \pm 0.172^{*}$ & $1.021 \pm 0.104^{*}$ \\
\hline Total & $1.020 \pm 0.103$ & $1.178 \pm 0.180$ & $1.100 \pm 0.0 .142^{*}, \#$ \\
\hline
\end{tabular}

PLI plaque index, $S B I$ sulcus bleeding index, $P D$ probing depth

Note: ${ }^{*}$, compared with the index level at baseline, $P<0.05$; ${ }^{\#}$, compared with the index level one month after treatment, $P<0.05$

${ }^{a}$ compared with the index level of the adolescents at baseline 


\section{Discussion}

Malocclusion is the common oral disease, with the continuous improvement of living quality, an obviously increasing trend can be observed in individuals who require for orthodontic treatment [23-25]. In-depth understanding of clinical and microbiological changes during the process of malocclusion treatment is hence crucially necessary for the treatment and further prevention of periodontal diseases, which is applicable among different age groups. Under normal circumstances, most periodontal plaque microorganisms can be maintained relatively stable due to the semi-enclosed structure of gingival sulcus, but not the same with the placement of fixed orthodontic appliance [26, 27].

In this experiment, detection rates of four different pathogens were gradually increased from baseline to one month and lately three months after treatment. Upward trends were also showed in children, significantly higher at the time point of the third month after treatment than that at baseline, whereas it was stable in 46 adults. In addition, the percentage of pathogens in the overall samples increased with time especially at the time point of the third month after treatment, gradual upward trends were found both in adults and children. We may know obviously, along with the extension of treatment time, orthodontic appliance placement will change the survival condition of subgingival microorganisms and promote the propagation of the periodontal pathogen, which in turn create favorable conditions for the onset of periodontal diseases [28]. Thus it could be illustrated out that fixed orthodontic appliance might have significant different influence in microecological environment for adults and children. Under the stimulation of orthodontic appliance and due to plaque accumulation, children' subgingival pathogens proliferation was more obvious than that in adults.

Periodontal clinical indicators were also detected in this experiment. Mandibular central incisors and premolars were determined as the object of observation, largely due to the short clinical crown and the relatively short distance of gums after direct bonding of bracket, which in turn might be vulnerable to the interference to produce inflammation. According to the experimental results, PLI of the total samples increased gradually, same results were also detected in the adults and the children subgroups. At baseline, children' PLI was significantly higher than that of adults, which might be correlated with the reason that adults had a generally positive attitude and habits towards oral health care [29, 30]. With the start of treatment, the differences of PLI in adults and children were not obvious, which might due to the effect of the caregivers' oral health education, and children paid more attention to oral and dental health care $[31,32]$. With the extension of treatment time, PLI was speculated to be further decreased or maintained at a stable level, which should be confirmed by further longterm investigation. Further, SBI also showed a significant difference at the first and third months than that at baseline, but no significant difference were found between adult and children subgroups as well as between different time points of the first and third month. This might indicated that inflammatory reaction might be occurred in the initial stage of orthodontic treatment [33], but then stabilized and without persistent deterioration during the following periods, more investigation should be conducted to confirm such speculation with the detection of inflammatory related parameters. Sharma NC et al. mentioned in their study that both PLI and SBI were decreased following the treatment process for children applied fixed orthodontic appliances, which was suggested to have beneficial results for the reduction of plaques and bleeding [34]. This in turn suggested the important role of clinical indexes monitoring. In addition, $\mathrm{PD}$ is an important indicator to measure periodontal health $[35,36]$. In this experiment, PD of the lower central incisors in all patients were within the healthy range during the whole observation period ( $\leq 2 \mathrm{~mm}$ ), also none obvious $\mathrm{AL}$ changes were observed over the period of observation. Although there was a marked increase of PD in the first month after treatment than that at baseline, post-treatment results showed that the average value of the third month was slightly lowered than that of the first month. In addition, comparison results indicated that between different subjects, the adults' PD was significantly higher than that in children at baseline, but there was no significant difference one month or three months after treatment.

\section{Conclusions}

In conclusion, fixed orthodontic appliances may have an influence in the periodontal and microbiological statuses of malocclusion patients both in adults and children. Some microbiological indexes indicate synchronous trends with clinical indexes. In addition, the effect of fixed orthodontic appliances may be more significant in children than in adults. The effect of fixed orthodontic appliances still needed further research in the long run.

\section{Abbreviations \\ AL: Attachment loss; F. nucleatum: Fusobacterium nucleatum; P. intermedia: Prevotella intermedia; P.gingivalis: Porphyromonas gingivalis; PD: Probing depth; PLI: Plaque index; real-time PCR: Real-time polymerase chain reaction; SBI: Sulcus bleeding index; T. forsythensis: Tannerella forsythensis}

\section{Acknowledgements}

We would like to doctors and nurses from Ninth Hospital of Xi'an for helping data and blood sample collection. We also thank the reviewers for their precious comments on this paper. The authors have no financial and nonfinancial conflicts of interest to declare. 


\section{Funding}

No Funding.

\section{Availability of data and materials}

The datasets analyzed during the current study are available from the corresponding author on reasonable request.

\section{Authors' contributions}

GL: writing of the manuscript. GL, FY: analysis and interpretation of the results. GL: Design of the study. GL, FY, and GHG: carried out the experiments. GL, FY, LBW, and ZY: performed the statistical analysis. All authors read and approved the final manuscript.

\section{Competing interests}

The authors declare that they have no competing interests.

\section{Consent for publication}

Not applicable.

\section{Ethics approval and consent to participate}

The Institutional Ethics Committee of Ninth Hospital of Xi'an approved the study. Study subjects and their parents/guardians signed an informed consent allowing themselves and their children to participants in the oral examinations. The methods were carried out in accordance with the approved guidelines.

\section{Author details}

'Department of Stomatology, Ninth Hospital of Xi'an, No. 151, 2nd Ring Road East, Xi'an 710054, People's Republic of China. ${ }^{2}$ Department of Orthopedic, Engineering University Hospital of PAPF, Xi'an 710086, People's Republic of China. ${ }^{3}$ Department of Orthodontics, School of Stomatology, China Medical University, Shenyang, China.

Received: 25 September 2016 Accepted: 20 October 2016

Published online: 28 October 2016

\section{References}

1. Golden BA, Baldwin C, Sherwood C, Abdelbaky O, Phillips C, Offenbacher S, White Jr RP. Monitoring for periodontal inflammatory disease in the third molar region. J Oral Maxillofac Surg. 2015;73(4):595-9.

2. Price JB, Thaw KL, Tyndall DA, Ludlow JB, Padilla RJ. Incidental findings from cone beam computed tomography of the maxillofacial region: a descriptive retrospective study. Clin Oral Implants Res. 2012;23(11):1261-8.

3. Scala A, Auconi P, Scazzocchio M, Caldarelli G, McNamara JA, Franchi L. Using networks to understand medical data: the case of Class III malocclusions. PLoS One. 2012;7(9):e44521.

4. Ehsani S, Nebbe B, Normando D, Lagravere MO, Flores-Mir C. Dental and skeletal changes in mild to moderate Class II malocclusions treated by either a Twin-block or Xbow appliance followed by full fixed orthodontic treatment. Angle Orthod. 2015:85(6):997-1002.

5. Abed Al Jawad F, Cunningham SJ, Croft N, Johal A. A qualitative study of the early effects of fixed orthodontic treatment on dietary intake and behaviour in adolescent patients. Eur J Orthod. 2012:34(4):432-6.

6. Zanatta FB, Ardenghi TM, Antoniazzi RP, Pinto TM, Rosing CK. Association between gingival bleeding and gingival enlargement and oral healthrelated quality of life (OHRQoL) of subjects under fixed orthodontic treatment: a cross-sectional study. BMC Oral Health. 2012;12:53.

7. Khanpayeh E, Jafari AA, Tabatabaei Z. Comparison of salivary Candida profile in patients with fixed and removable orthodontic appliances therapy. Iran J Microbiol. 2014;6(4):263-8.

8. Behr M, Zeman F, Baitinger T, Galler J, Koller M, Handel G, Rosentritt M. The clinical performance of porcelain-fused-to-metal precious alloy single crowns: chipping, recurrent caries, periodontitis, and loss of retention. Int J Prosthodont. 2014;27(2):153-60.

9. Liu P, Liu Y, Wang J, Guo Y, Zhang Y, Xiao S. Detection of fusobacterium nucleatum and fadA adhesin gene in patients with orthodontic gingivitis and non-orthodontic periodontal inflammation. PLoS One. 2014;9(1):e85280.

10. Yang NY, Zhang Q, Li JL, Yang SH, Shi Q. Progression of periodontal inflammation in adolescents is associated with increased number of Porphyromonas gingivalis, Prevotella intermedia, Tannerella forsythensis, and Fusobacterium nucleatum. Int J Paediatr Dent. 2014;24(3):226-33.
11. Liu Y, Zhang Y, Wang L, Guo Y, Xiao S. Prevalence of Porphyromonas gingivalis four rag locus genotypes in patients of orthodontic gingivitis and periodontitis. PLoS One. 2013;8(4):e61028.

12. Bizzini B, Pizzo G, Scapagnini G, Nuzzo D, Vasto S. Probiotics and oral health. Curr Pharm Des. 2012;18(34):5522-31.

13. Grabowski R, Stahl F, Gaebel M, Kundt G. Relationship between occlusal findings and orofacial myofunctional status in primary and mixed dentition. Part I: prevalence of malocclusions. J Orofac Orthop. 2007;68(1):26-37.

14. Oliveira AC, Paiva SM, Campos MR, Czeresnia D. Factors associated with malocclusions in children and adolescents with Down syndrome. Am J Orthod Dentofacial Orthop. 2008;133(4):489 e1-8.

15. Sllness J, Loe H. Periodontal disease in pregnancy. Acta Odontol Scand. 1964;22:121-35.

16. Al-Nawas B, Bragger U, Meijer HJ, Naert I, Persson R, Perucchi A, Quirynen M, Raghoebar GM, Reichert TE, Romeo E, et al. A double-blind randomized controlled trial (RCT) of Titanium-13Zirconium versus Titanium Grade IV small-diameter bone level implants in edentulous mandibles-results from a 1-year observation period. Clin Implant Dent Relat Res. 2012;14(6):896-904.

17. Schwarz F, John G, Mainusch S, Sahm N, Becker J. Combined surgical therapy of peri-implantitis evaluating two methods of surface debridement and decontamination. A two-year clinical follow up report. J Clin Periodontol. 2012;39(8):789-97.

18. Haas AN, Gaio EJ, Oppermann RV, Rosing CK, Albandar JM, Susin C. Pattern and rate of progression of periodontal attachment loss in an urban population of South Brazil: a 5-years population-based prospective study. J Clin Periodontol. 2012;39(1):1-9.

19. Eick S, Straube A, Guentsch A, Pfister W, Jentsch H. Comparison of real-time polymerase chain reaction and DNA-strip technology in microbiological evaluation of periodontitis treatment. Diagn Microbiol Infect Dis. 2011;69(1): 12-20.

20. Patterson JL, Stull-Lane A, Girerd PH, Jefferson KK. Analysis of adherence, biofilm formation and cytotoxicity suggests a greater virulence potential of Gardnerella vaginalis relative to other bacterial-vaginosis-associated anaerobes. Microbiology. 2010;156(Pt 2):392-9.

21. Okamoto M, Maeda N, Kondo K, Leung KP. Hemolytic and hemagglutinating activities of Prevotella intermedia and Prevotella nigrescens. FEMS Microbiol Lett. 1999;178(2):299-304.

22. Cortelli JR, Pinheiro RMS, Costa FDO, Aquino DR, Raslan SA, Cortelli SC, Cortelli JR, Pinheiro RMS, Costa FDO, Aquino DR. Salivary and microbiological parameters of chronic periodontitis subjects with and without type 2 diabetes mellitus: a case-control study. Revodontolunesp. 2014:43(3):196-202.

23. Choi SH, Kim Bl, Cha JY, Hwang CJ. Impact of malocclusion and common oral diseases on oral health-related quality of life in young adults. Am J Orthod Dentofacial Orthop. 2015;147(5):587-95.

24. Aldrigui JM, Abanto J, Carvalho TS, Mendes FM, Wanderley MT, Bonecker M, Raggio DP. Impact of traumatic dental injuries and malocclusions on quality of life of young children. Health Qual Life Outcomes. 2011;9:78.

25. Chen $\mathrm{CH}$, Wang TY, Tsay PK, Lai JB, Chen CT, Liao HT, Lin CH, Chen YR. A 162-case review of palatal fracture: management strategy from a 10-year experience. Plast Reconstr Surg. 2008;121(6):2065-73.

26. Adler CJ, Dobney K, Weyrich LS, Kaidonis J, Walker AW, Haak W, Bradshaw CJ, Townsend G, Soltysiak A, Alt KW, et al. Sequencing ancient calcified dental plaque shows changes in oral microbiota with dietary shifts of the Neolithic and Industrial revolutions. Nat Genet. 2013;45(4):450-5. 5e1.

27. Takahashi N, Nyvad B. The role of bacteria in the caries process: ecological perspectives. J Dent Res. 2011;90(3):294-303.

28. Potârnichie O, Solomon S, Păsărin L, Mârțu A, Ursărescu I, Nițescu DC, Mârțu S. Statistical study regarding the prevalence of the periodontal pathology on the teenager patient. Romanian J Oral Rehabilit. 2013;5(2):80.

29. Mackenzie CS, Erickson J, Deane FP, Wright M. Changes in attitudes toward seeking mental health services: a 40-year cross-temporal meta-analysis. Clin Psychol Rev. 2014;34(2):99-106.

30. Wardh I, Jonsson M, Wikstrom M. Attitudes to and knowledge about oral health care among nursing home personnel-an area in need of improvement. Gerodontology. 2012;29(2):e787-92.

31. Gambhir RS, Sohi RK, Nanda T, Sawhney GS, Setia S. Impact of school based oral health education programmes in India: a systematic review. J Clin Diagn Res. 2013;7(12):3107-10.

32. Guarnizo-Herreno CC, Wehby GL. Children's dental health, school performance, and psychosocial well-being. J Pediatr. 2012;161(6):1153-9. 
33. Gupta M, Kandula S, Laxmikanth SM, Vyavahare SS, Reddy SB, Ramachandra CS. Controlling pain during orthodontic fixed appliance therapy with nonsteroidal anti-inflammatory drugs (NSAID): a randomized, double-blinded, placebo-controlled study. J Orofac Orthop. 2014;75(6):471-6.

34. Sharma NC, Lyle DM, Qaqish JG, Galustians J, Schuller R. Effect of a dental water jet with orthodontic tip on plaque and bleeding in adolescent patients with fixed orthodontic appliances. Am J Orthod Dentofacial Orthop. 2008;133(4):565-71. quiz 628 e1-2.

35. Shaffer JR, Polk DE, Wang X, Feingold E, Weeks DE, Lee MK, Cuenco KT, Weyant RJ, Crout RJ, McNeil DW, et al. Genome-wide association study of periodontal health measured by probing depth in adults ages 18-49 years. G3 (Bethesda). 2014;4(2):307-14.

36. Ishihata K, Wakabayashi N, Wadachi J, Akizuki T, Izumi Y, Takakuda K, Igarashi Y. Reproducibility of probing depth measurement by an experimental periodontal probe incorporating optical fiber sensor. J Periodontol. 2012; 83(2):222-7.

Submit your next manuscript to BioMed Central and we will help you at every step:

- We accept pre-submission inquiries

- Our selector tool helps you to find the most relevant journal

- We provide round the clock customer support

- Convenient online submission

- Thorough peer review

- Inclusion in PubMed and all major indexing services

- Maximum visibility for your research

Submit your manuscript at www.biomedcentral.com/submit
Biomed Central 